\title{
"Me gusta "la selva" porque es un sitio salvaje, donde me puedo esconder»: el uso de la fotografía participativa en las geografías de la infancia
}

\author{
Noelia Ceballos López \\ Teresa Susinos Rada \\ Universidad de Cantabria. Departamento de Educación \\ noelia.ceballos@unican.es \\ susinost@unican.es
}

Recibido: septiembre de 2017

Aceptado: diciembre de 2017

Publicado: enero de 2019

\section{Resumen}

Esta investigación se enmarca en las geografías de la infancia escolarizada y explora los significados que los estudiantes asignan a los espacios que ellos prefieren en la escuela, los usos que les atribuyen y los modos de relación que propician. Ello se propone como una expresión más de la agencia de los alumnos y de la necesidad de escuchar su voz en los procesos democráticos de mejora académica. Bajo un modelo de investigación cualitativa, el trabajo se sirve de la fotografía participativa como instrumento para registrar las ideas de los niños y niñas y estimular el diálogo. Los resultados se centran en analizar las posibilidades que nos ofrece dicha metodología para la investigación de las geografías de la infancia escolarizada a la luz de la experiencia que se presenta. El artículo también discute qué significados asignan los estudiantes a los espacios elegidos, por qué hay espacios físicos como las aulas que no son considerados, qué relaciones facilitan y dificultan estos lugares, qué significados tienen ciertas zonas minoritarias y cómo los estudiantes resignifican algunos rincones anodinos para los adultos y los conectan con sus propios intereses y prioridades.

Palabras clave: geografías de la infancia; fotografía participativa; espacios escolares; educación primaria 
Resum. "M'agrada "la selva" perquè és un lloc salvatge, on em puc amagar»: l'ús de la fotografia participativa en les geografies de la infancia

Aquesta recerca s'emmarca en les geografies de la infancia escolaritzada i explora els significats que els estudiants assignen als espais que ells prefereixen de l'escola, els usos que els atribueixen i els tipus de relacions que propicien. Es proposa com una expressió més de l'agència de l'alumnat i de la necessitat d'escoltar la seva veu en els processos democràtics de millora acadèmica. Sota un model de recerca qualitativa, el treball se serveix de la fotografia participativa com a instrument per registrar les idees dels nens i nenes i estimular el diàleg. Els resultats se centren a analitzar les possibilitats que ens ofereix aquesta metodologia per cercar les geografies de la infancia escolaritzada en vista de l'experiència que s'hi presenta. L'article també discuteix quins significats assignen els estudiants als espais triats, per què hi ha espais físics com ara les aules que no hi són considerats, quines relacions faciliten i dificulten aquests llocs, quins significats tenen certs indrets minoritaris i com els estudiants resignifiquen alguns racons anodins per als adults i els connecten amb els seus propis interessos i prioritats.

Paraules clau: geografies de la infancia; fotografia participativa; espais escolars; educació primària

Résumé. "La "forêt" me plaît parce que c'est un endroit sauvage, où se cacher " : l'utilisation de la photographie participative dans les géographies de l'enfance

Cette recherche s'inscrit dans le cadre des géographies de l'enfance scolarisée et explore les significations que les élèves assignent aux espaces scolaires, à leurs usages, à leurs relations et aux interactions que ceux-ci leur permettent, dans l'objectif de constituer une expression de l'agencement des élèves et de la nécessité d'écouter leur voix dans les processus démocratiques de l'amélioration de l'école. Ce travail s'appuie sur une recherche qualitative en faisant usage de la photographie participative comme un instrument pour enregistrer les idées des étudiants et stimuler le dialogue. Les résultats portent sur l'analyse des possibilités offertes par cette méthodologie pour l'étude des géographies de l'enseignement à la lumière de l'expérience présentée. L'article discute également quelles significations sont attribuées par les élèves aux sites choisis, pourquoi il y a des espaces physiques tels que les salles de classe qui ne sont pas considérés, quelles relations facilitent et font obstacle à ces espaces, quelles significations sont attribués à certains espaces minoritaires et comment les élèves redéfinissent certains endroits anodins pour les adultes et les relient à leurs propres intérêts et priorités.

Mots-clés: géographies de l'enfance; photographie participative; espaces scolaires; éducation primaire

Abstract. "I like 'the jungle' because it is a wild place where I can hide": The use of participatory
photography in children's geographies

This research is framed in school children's geographies and explores the meanings that students assign to school spaces, as well as the uses they attribute to them and the interactions they foster. This is proposed as an expression of students' agency and the need to listen to their voice in the democratic processes of school improvement. Relying on a qualitative research model, participatory photography is used as an instrument to record student's ideas and stimulate dialogue. The results reveal the possibilities this methodology offers for investigating school children's geographies in light of the experience presented. The article also discusses why there are physical spaces such as classrooms that are not 
considered, what relationships these spaces facilitate and hinder, what meanings certain minority spaces have, and how students resignify some nondescript places for adults and connect them with their own interests and priorities.

Keywords: children's geographies; participatory photography; school spaces; primary education

\author{
Sumario \\ 1. Introducción 4. Conclusiones \\ 2. Metodología de la investigación Referencias bibliográficas \\ 3. Resultados y discusión
}

\title{
1. Introducción
}

En la década de 1980, especialmente en el contexto anglosajón, surgieron los primeros estudios culturales ligados a la geografía cuyo interés era comprender las prácticas espaciales y sociales que experimentaban los diversos colectivos en la esfera pública, lo que permitía visibilizar las oportunidades desiguales de poder, uso y autonomía a las que tenían acceso (Matthews y Limb, 1999; Ortiz, 2007). Durante la década de 1990, esta corriente confluye con los estudios de la infancia como colectivo y surge el ámbito de estudio de la geografía de la infancia, encargada de analizar la vida cotidiana de los niños y jóvenes, el uso, la ocupación y las actividades que realizan en los espacios y cómo estas experiencias contribuyen a construir sus identidades (Phillips, 2001; Ortiz, 2007; Ortiz et al., 2012). Bajo este propósito común han tenido lugar investigaciones de temáticas, perspectivas y enfoques diversos que analizan los espacios ocupados, imaginados y deseados por la infancia; aquellos donde está excluida o marginada; públicos o privados; urbanos o rurales; del Norte global o del Sur global, etc. (Horton, et al., 2008; Ortiz et al., 2012; Robson et al., 2013).

Dichas investigaciones se sitúan en el campo de la geografía, pero, como ha mostrado Holloway (2014), han actuado desde diferentes perspectivas dependiendo del momento histórico y cultural, siendo en menor medida un foco de interés para los estudios educativos, tal y como proponemos en este artículo. Por ello, en un intento de contribuir al debate de las geografías de la infancia desde una óptica educativa, presentamos esta investigación llevada a cabo en una escuela pública de Cantabria (España ${ }^{1}$ con alumnado de segundo y sexto

1. Proyecto de investigación «Escuelas que caminan en la dirección inclusiva: aprendiendo de la comunidad local, la voz del alumnado y el apoyo educativo", financiado por el MICINN (Ref. EDU2011-29928-C03-03) y dirigido por la Dra. Teresa Susinos. En el marco de dicho proyecto se desarrolló la tesis doctoral que lleva por título Diseño, desarrollo y evaluación de cinco experiencias de voz del alumnado en escuelas de Cantabria (España). Propuesta de una guía para centros educativos. Fue desarrollada bajo la dirección de la Dra. Teresa Susinos 
de educación primaria. Estos estudiantes indagan juntos sobre los espacios del centro, su uso y su ocupación, reflexionando sobre las actividades que habitualmente desempeñan en esos lugares, las relaciones que se establecen entre ellos y con dichos espacios y los recursos que encuentran disponibles para poder actuar. El objetivo fundamental del presente artículo es, por tanto, avanzar en la comprensión acerca de cómo los estudiantes viven y significan los espacios comunes de su escuela, centrando la atención en los aspectos físicos, pero también en las relaciones, las actividades, los usos y los procesos que en ellos acontecen; cuáles son las mejoras que proponen y qué sentido tienen estas propuestas para comprender con mayor profundidad la relación que los sujetos establecen con sus espacios cotidianos. Este propósito se conecta en última instancia con las investigaciones sobre la voz del alumnado (student voice) que venimos desarrollando (Susinos y Ceballos, 2012; Susinos y Haya, 2014; Ceballos, Susinos y Saiz, 2016). El análisis conjunto con los estudiantes acerca de los usos y de los significados que atribuyen a los espacios escolares es un vehículo de reconocimiento de la agencia de los alumnos en la mejora de los espacios que habitan, de su experiencia y de los procesos de resignificación que se derivan de su uso cotidiano. Todo ello es de gran valor para propuestas de cambio y de mejora escolar que sean verdaderamente democráticas.

\subsection{Las geografias de la infancia}

La aprobación de la Convención sobre los Derechos de la Infancia (1989) supuso una acción clave en el desarrollo de las geografías de la infancia. En primer lugar, porque el acceso, el uso y la ocupación de los lugares públicos por parte de la infancia se presentó como un derecho legítimo. En segundo lugar, porque el reconocimiento del derecho a participar en la toma de decisiones de los asuntos que les afectan (artículo 12) desveló la ausencia de la infancia en el diseño de los espacios públicos y reclamó su inclusión en los procesos de diseño (Matthews y Limb, 1999). Si bien se ha visto aumentada la presencia de los niños y las niñas en la planificación y el diseño de espacios, con demasiada frecuencia esta ha sido marginal y meramente simbólica.

En segunda instancia, el interés por entender cómo experimenta e interpreta la infancia los espacios escolares surge del reconocimiento de esta como sujeto social con capacidad expresiva, así como de la comprensión de los espacios y ambientes educativos como marco en el que se generan las oportunidades de aprender, interactuar, relacionarse y experimentar (Abad, 2006). Reconocemos que la experiencia de infancia y el significado que se le otorga no es única, sino que responde a una construcción situada cultural y socialmente. En consecuencia, surge la consideración de la existencia de "múltiples infancias» y, por tanto, múltiples geografías de la infancia que responden a la amplitud

y con la financiación del Ministerio de Economía y Competitividad a través de la obtención de una beca-contrato para la Formación de Personal Investigador (FPI) con referencia BES-2012-059084. 
de experiencias sociales y espaciales que experimentan los niños y niñas en su vida cotidiana en el mundo e incluso en un mismo contexto social (Matthews y Limb, 1999; Ortiz, 2007).

Igualmente, esta investigación parte de la consideración de la agencia de la infancia para construir significados (Kincheloe, 2007; Clark, 2010) y, en particular, del reconocimiento de su experiencia escolar y su valor insustituible para comprender y mejorar los espacios educativos. Ello supone un cambio en la visión tradicional de la infancia como tiempo de espera, inmadurez y dependencia.

Nos enfrentamos al reto de reconocer que la forma en la que los niños y niñas significan y viven el espacio físico y arquitectónico difiere del uso que habitualmente realiza de él la mayoría de los adultos, pero también que hay modos individuales de significar estos lugares que no siempre son compartidos por todos los compañeros. Por ello es necesario escuchar su voz, con el interés genuino que despierta el testimonio de quienes son testigos expertos, para comprender las múltiples miradas e interpretaciones que existen sobre los espacios comunes y que son inaccesibles desde la posición del adulto.

\subsection{La fotografía participativa como estrategia para explorar las geografias de la infancia}

Para rastrear estas diferentes geografías de la infancia a las que aludimos, las investigaciones han hecho principalmente uso de técnicas de producción de datos de orientación cualitativa (Ortiz, 2007; Ortiz et al., 2012), aunque también encontramos trabajos que hacen uso de métodos cuantitativos (SmoyerTomic et al., 2004) o mixtos (Maguire y Shirlow, 2005; Spilsbury, 2005). Entre las estrategias cualitativas más abundantes encontramos: técnicas de observación (Thomson, 2005); entrevistas y grupos de discusión (Giddings y Yarwood, 2005) o el uso de audios del pasado (Mills, 2017); técnicas digitales (Ergler et al., 2016), y métodos visuales, como los dibujos (Ortiz et al., 2012), la fotografía aérea o la fotografía (Tucker, 2003; Cooper, 2017).

En esta investigación iniciamos la búsqueda de un lenguaje común y accesible para los estudiantes que nos permitiera acceder a las interpretaciones y a los significados de todo el alumnado. Ello nos llevó a adoptar los procesos de documentación pedagógica a través de la fotografía participativa (Wang, 2003; Wang y Burris, 1994; Prins, 2010).

La fotografía participativa o fotovoz es definida como una metodología de investigación participativa que permite a los sujetos, principalmente aquellos cuya voz es menos reconocida, narrar sus experiencias y producir conocimiento sobre su contexto circundante (Wang, 2003; Prins, 2010). Como señalan Wang y Burris (1994), la fotografía participativa posee tres características esenciales: la primera es que permite a las personas registrar y visualizar sus ideas, preocupaciones e interpretaciones sobre el objeto de estudio a través de imágenes. En segundo lugar, las fotografías se convierten en objetos de análisis y construcción de conocimiento a través de estrategias de diálogo, reflexión, 
crítica e intersubjetividad (Novak, 2010). Por último, la fotografía participativa es un medio de difusión, una estrategia para hacer llegar propuestas a quienes tienen el poder de promover cambios. Cuando los alumnos disponen de una cámara para documentar, las instantáneas realizadas, además de ofrecer su particular mirada del mundo, presentan a la audiencia la oportunidad de entender su posición social y física en él. La fotografía participativa ofrece la oportunidad de explorar la realidad haciendo uso del lenguaje visual, permite desvelar representaciones no siempre accesibles con otros lenguajes y comunicar ideas de forma significativa para los protagonistas (Tolfree y Woodhead, 1999; Clark, 2010).

Las fotografías no constituyen un reflejo fiel de la realidad ni representaciones únicas y homogéneas, sino miradas particulares, formas de ver, de entender, de interpretar y de compartir una experiencia, un espacio, una realidad (Berger, 1972). Esto nos recuerda que también la voz del alumnado es provisional, múltiple y se encuentra en desarrollo. Pensar que existe una única voz que representa a todo el alumnado nos llevaría a alimentar la hegemonía de aquellos jóvenes que dominan el lenguaje de la escuela y conocen y respetan las normas de la misma, lo cual no es el objetivo del presente trabajo.

Así mismo, las fotografías, tanto en su producción como en su análisis, responden a procesos de percepción, intencionalidad, selección, registro e interpretación y, por tanto, son miradas de la realidad abiertas a múltiples lecturas e interpretaciones (Banks, 2010). Por ello, el diálogo nos permitió compartir significados y comprender cómo los estudiantes resignificaban algunos espacios, lo que promovió nuevos usos y experiencias no homogéneas de dichos lugares de la escuela (Wang, 2003; Thomson, 2008; Clark, 2010; Niemi et al., 2015). En consecuencia, se creó un diálogo compartido sobre los espacios educativos que permitió visibilizar y revisar las prácticas cotidianas y analizar qué procesos y qué relaciones tenían lugar en las mismas colectivamente.

Por último, la fotografía participativa se convirtió en una estrategia para visibilizar las ideas del alumnado y, por tanto, en un mecanismo para ganar agencia y voz en la escuela, con el fin último de avanzar en su gestión democrática.

Sin embargo, la fotografía participativa plantea algunos dilemas éticos (Wang y Burris, 1994; Sanon et al., 2014; Prins, 2010), por ejemplo, en torno a la confidencialidad de las imágenes o al consentimiento informado de los protagonistas. El alumnado fue informado sobre el propósito del estudio y sus fases, así como sobre la intención de que finalmente las imágenes fueran expuestas en el vestíbulo del centro, siempre previo consentimiento por su parte.

\section{Metodología de la investigación}

Tal y como venimos mostrando, el presente trabajo se enmarca en la tradición de la investigación cualitativa que busca comprender críticamente y en profundidad los fenómenos sociales estudiados, en este caso las geografías de la infancia en el contexto escolar. 
La investigación se llevó a cabo en una escuela pública de educación infantil y primaria de Cantabria (España), en la que participaron dos aulas de educación primaria (de segundo y de sexto curso), sus dos tutoras y un total de 46 alumnos. El protagonismo de los niños y las niñas en el proceso de producción de datos a través de la construcción y de la interpretación de las imágenes es lo que les ha permitido desempeñar su papel como coinvestigadores de su realidad (Fielding, 2011; Bucknall, 2012).

En el desarrollo de esta investigación, el alumnado hizo uso de la fotografía participativa (Wang, 2003; Wang y Burris, 1994; Banks, 2010), que, como ya hemos señalado, se desarrolla en tres momentos clave: la realización de las imágenes de manera individual; el momento posterior de diálogo sobre las mismas que nos permitió compartir interpretaciones y construir un diálogo colectivo sobre los espacios escolares, y, por último, la difusión de las imágenes.

Complementariamente, se utilizaron otras técnicas de orientación etnográfica: se realizaron dos entrevistas semiestructuradas a cada tutora, una al inicio de la experiencia y otra al final, que ascendieron a un total de cuatro (Kvale, 2011), y se recurrió también a la observación participante (Spradley, 1980 citado en Flick, 2009), con el propósito de documentar el proceso de producción de las imágenes, las dificultades y los apoyos encontrados, las relaciones establecidas entre el alumnado y el proceso de diálogo posterior sobre las instantáneas realizadas. Cada una de las observaciones dio lugar al diario de investigación.

Más tarde se llevó a cabo un análisis de los documentos producidos en la investigación (Flick, 2009), especialmente de las actas que los estudiantes elaboraron al final de las asambleas y de las entradas del blog en las que describían la experiencia.

Todos los datos anteriores fueron examinados a través de un proceso de categorización deductivo-inductivo (Gibbs, 2012) utilizando el programa MAXQDA (2010).

Por último, hay que destacar que la investigación está en la línea del código ético EECERA para los investigadores de la infancia, así como otras consideraciones aportadas por diversos autores (Dockett et al., 2009).

El proceso de investigación seguido se desarrolló de acuerdo con las siguientes fases:

\subsection{Asamblea: punto de partida}

El proyecto de investigación empezó con la presentación del tópico de trabajo "Mi lugar favorito del centro» en una asamblea conjunta en la que se encontraban los estudiantes de ambas aulas. En ella se describía el propósito de la investigación, que consistía en analizar los espacios escolares, su configuración física en aquel momento, el uso y la ocupación que los estudiantes hacían de ellos y los procesos, los modos de trabajo y las relaciones que se producían allí. Además, se inició un diálogo con el alumnado para decidir la configuración de las parejas de trabajo y cómo iba a desarrollarse la actividad. 
Se comenzó con un debate sobre si utilizar fotos o dibujos del espacio escolar elegido. Tras un proceso de diálogo, optaron por una instantánea que debía ir acompañada por un texto explicativo redactado por el autor de la imagen. La fotografía se eligió en vez del dibujo al considerarla una estrategia más versátil, ya que permitía realizar varias tomas en poco tiempo. De entre las diversas herramientas posibles, se optó por el uso de móviles y cámaras no profesionales. Estos aparatos de fotografía digital permitieron al alumnado realizar un número ilimitado de instantáneas, revisar sus imágenes en el momento mismo de hacer las tomas y evaluar su nivel de satisfacción con las mismas, a fin de aceptarlas o repetirlas.

Se propuso organizar el trabajo en parejas conformadas por un alumno de segundo de educación primaria y uno de sexto de la misma etapa. Esta agrupación surgió como estrategia de ayuda entre iguales en la búsqueda y en la producción de las fotografías y el texto. La configuración de las parejas recayó sobre los escolares, quienes se agruparon libremente siguiendo sus preferencias, con la única consideración de que debían trabajar con un compañero de la otra clase. Se crearon un total de veinte parejas y dos tríos (dos alumnos de sexto $\mathrm{y}$ uno de segundo).

Finalmente, la consigna recibida por las parejas fue «Fotografiar mi lugar favorito de la escuela». Cada uno podía tomar un número ilimitado de imágenes, pero finalmente debía elegir una de ellas. La imagen elegida se debía acompañar de un texto de extensión y estructura libre que había de responder a los epígrafes siguientes: «Descripción del lugar», «Actividades que habitualmente desarrollas ahí», «Personas con las que te relacionas en dicho espacio»y, por último, «Motivos de tu elección». Esta breve reseña escrita ejercía también funciones de etiquetado o subtitulado de la foto (captioning) (Barker y Smith, 2010), proceso en el que los mayores apoyaron a los más pequeños.

Para tomar las instantáneas, los estudiantes podían desplazarse libremente por todos los espacios escolares. No existían restricciones de movimiento, la única condición era que no podían interrumpir el trabajo de otros compañeros ni el de los profesores. Esta condición de acceso libre a toda la escuela permitió evitar que los niños y las niñas se vieran abocados a elegir «fotografías de oportunidad» (Croghan et al., 2008) que no respondieran de forma genuina con sus lugares preferidos, sino que estuvieran inducidas por las limitaciones en el acceso a determinados lugares físicos de su centro educativo.

\subsection{Taller de formación: ética y estética}

La actividad de captura de tomas fue precedida de dos talleres. El primero de ellos versó sobre los aspectos éticos propios de un proceso de indagación con fotografías. En él se resaltaba el respeto a la confidencialidad y el consentimiento de los sujetos que aparecían en las imágenes, especialmente si no participaban directamente en la experiencia (Parrilla, 2010; Bucknall, 2012). La asunción de este principio ético tuvo principalmente dos implicaciones: obligó al alumnado a construir una explicación accesible para cualquier persona sobre 
la experiencia y se optó, en diálogo con los estudiantes, que las fotografías que implicaran a personas ajenas a la actividad que se realizaba fuesen tomadas desde una distancia que no favoreciera su identificación.

El segundo encuentro sirvió para presentar algunas consideraciones estéticas básicas para la producción de imágenes, como los procesos de encuadre para que recogieran los aspectos más relevantes que querían mostrar o de luz y contraluz.

\subsection{Sesiones de fotografía por el centro}

Las parejas inician sus paseos por el centro con el fin de documentar su espacio favorito, así como recoger por escrito la descripción del mismo. Cabe recordar que cada alumno/a debía realizar su conjunto de imágenes, elegir la más representativa y argumentar sobre su elección personal. Ello requirió reflexionar con los estudiantes sobre las diferencias de poder que podían surgir entre ellos atendiendo a la influencia que los chicos y chicas de mayor edad ejerciesen en la elección de su compañero o compañera.

El hecho de que estuviesen implicadas dos aulas de diferentes niveles educativos influyó en la organización del tiempo escolar. Las maestras reservaron las dos últimas horas de la mañana del jueves en sus respectivos horarios durante siete meses para desarrollar el proyecto, lo que supuso una amplia inversión de tiempo, así como la reestructuración de las demás actividades y asignaturas en el horario escolar.

\subsection{Diálogo colectivo sobre las fotografías}

Una vez que cada escolar había elaborado y seleccionado la imagen y el texto sobre su espacio favorito, las fotografías fueron objeto de análisis a través de estrategias de diálogo, reflexión, crítica e intersubjetividad (Novak, 2010).

Para tal fin, se organizó una asamblea conjunta en la que participó el alumnado de ambas clases y las dos tutoras. Cada una de las imágenes producidas se recogió en un panel que permitía visualizar un mapa de los espacios documentados. De manera individual, cada escolar mostraba su fotografía, describía el espacio, los materiales, los juegos, las actividades y las relaciones que en él acontecían, así como las razones de su elección. Esta acción promovía un diálogo entre los estudiantes sobre el espacio en el que se contrastaban las diversas miradas y las diferentes actividades, las relaciones y los usos que en él se enmarcaban. En ocasiones, como veremos en los resultados, se producían interpretaciones contrapuestas sobre un mismo espacio. Las reflexiones que surgían eran recogidas en un acta elaborada por el alumnado. En definitiva, en esta asamblea, a través del diálogo sobre las imágenes, se produjo un momento de reflexión y reinterpretación más compleja y colectiva de los espacios educativos (Wang, 2003; Doval et al., 2013).

Para el desarrollo de este proceso de construcción colectiva de significados es clave garantizar una organización y un clima que posibilite que todos 
expresen su opinión, especialmente aquellos que habitualmente ven limitada su participación. Para ello, se comenzó por confirmar la presencia de todos, eligiendo un momento de la jornada escolar que permitiera su participación sin discriminación alguna. Igualmente se dispuso de un tiempo compartido por ambos grupos, en este caso dos horas, que fuera holgado, sin la prisa habitual de un horario parcelado para permitir que todo el mundo pudiera opinar. Por último, se eligió un espacio amplio y amigable para albergar a los dos grupos.

\subsection{Evaluación y difusión. Cuestionario en línea, panel en el centro y blog}

Para llevar a cabo la evaluación de la experiencia, el alumnado diseñó y respondió un cuestionario en línea. Este estaba compuesto por cinco preguntas de diversa naturaleza (escalas Likert y respuestas abiertas) que se centraban en una valoración general acerca del valor del proyecto. La valoración de las maestras se materializó en entrevistas semiestructuradas con cada una de ellas.

Por otro lado, la difusión del trabajo realizado se llevó a cabo a través del panel con fotografías que fue colocado en el vestíbulo del centro y a través del blog del aula. El panel pretendía dar a conocer la experiencia al resto de alumnos y docentes. En él, los estudiantes situaron las fotografías, así como algunas de las reflexiones sobre los espacios que habían recogido en sus anotaciones y en el diálogo posterior. De este modo, se evidenció una de las características de la metodología de la fotografía participativa: su función comunicativa, es decir, la posibilidad de utilizar las imágenes como herramientas para trasladar mensajes a otros.

El blog del aula, que venía ya funcionando a modo de diario digital ${ }^{2}$, pretendía ser un medio de difusión de mayor alcance que permitiera que las familias y la comunidad educativa local accedieran a un relato de lo acontecido. En él presentaban una narración sobre algunas sesiones que acompañaban de fotografías que cumplían una función ilustrativa. En definitiva, no pretendían secuenciar cada una de las acciones, sino dar cuenta de lo que la experiencia había significado para ellos.

\section{Resultados y discusión}

Los principales resultados de la investigación serán presentados aquí organizándolos en dos apartados. En primer lugar, nos interrogaremos sobre el papel que tuvo la fotografía participativa como estrategia para investigar las geografías de la infancia en esta investigación. En un segundo momento, abordamos qué nos dicen los estudiantes sobre la vivencia de los espacios escolares que habitan, sus usos, las relaciones que en ellos establecen y su significación.

2. <http://investigandoparamejorar.blogspot.it/>. 


\subsection{El papel de la fotografía participativa como estrategia para investigar las geografias de la infancia}

La fotografía participativa se presentó como una estrategia valiosa para la documentación, la construcción y la visualización de las múltiples miradas que tiene el alumnado sobre los espacios y la vida escolar (Wang, 2003; Wang y Burris, 1994). En este proceso encontramos diferentes usos de las imágenes que han contribuido de forma muy relevante a conseguir nuestro propósito último de reconocer y recuperar la voz de los estudiantes en la escuela. Por un lado, la fotografía ha actuado como contenedora de las ideas, las preferencias y los significados que cada alumno y cada alumna otorga a los espacios escolares; por otro lado, ha sido el instrumento promotor del diálogo y la reinterpretación colectiva de los lugares elegidos, y, finalmente, ha constituido un valioso medio de difusión de todo el proceso entre audiencias más próximas al colegio y más alejadas de él.

\subsubsection{La fotografia participativa como estrategia que permite expresar visiones individuales}

La fotografía participativa se presenta, en primer lugar, como un instrumento adecuado y útil para registrar las visiones personales que cada estudiante ha construido acerca de los espacios de la escuela y en particular de sus lugares preferidos. En este sentido, se nos presenta como una herramienta sencilla, accesible y con la que los estudiantes se encuentran muy familiarizados, lo cual la convierte en un buen instrumento de inclusión que facilita que todos los estudiantes sin excepción puedan expresar su experiencia a través de las imágenes.

Daniel $^{3}\left(6^{\circ}\right)$ cuenta que él ha elegido fotografiar la pista porque es el sitio donde más se juega: al fútbol, pilla-pilla. «La foto es para enseñar dónde me gusta jugar», comenta.

Durante el proceso de producción de las fotografías, el alumnado se vio obligado a tomar numerosas decisiones que eran relevantes para determinar cuál sería el producto final que iba a presentar a sus compañeros y compañeras.

El uso de herramientas digitales facilitó que los escolares evaluasen las fotografías en el momento de su realización. Esto generó que el número de imágenes que tomaron fuera variado. Algunos optaron por hacer dos o tres instantáneas, y otros, más de diez. Esta diversidad generó diferencias respecto al tiempo necesario para tomar las imágenes y respecto a las posibilidades posteriores de seleccionar la fotografía más representativa, si bien todos hicieron uso libre del número de exposiciones que deseaban llevar a cabo, tanto de espacios como de encuadres.

Esta variedad en el número de instantáneas responde en alguna medida a que, mientras algunos alumnos las realizaron teniendo una idea previa de

3. Con el fin de respetar el anonimato de las personas que expresaron su opinión, los nombres que aparecen son ficticios, aunque mantienen el género de los sujetos. 
Imagen 1. Imágenes sobre el proceso de toma de fotografías y elaboración del texto

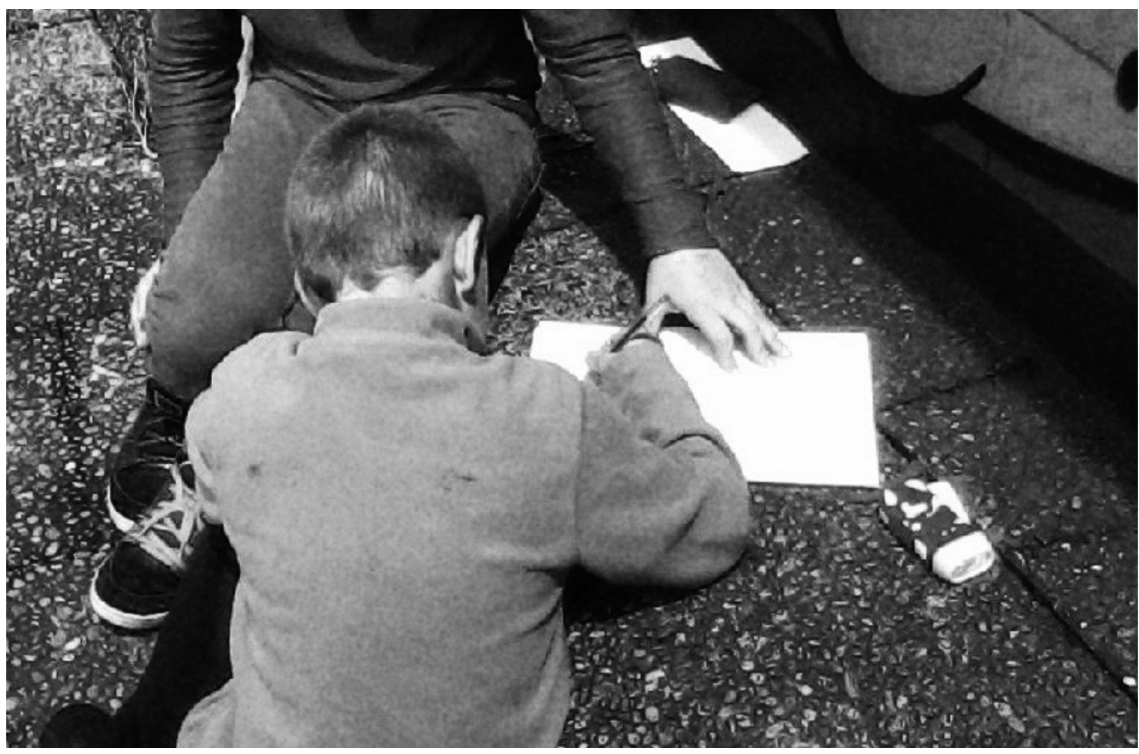

Fuente: elaboración propia.

cómo debían de ser, la mayoría tomó fotografías diferentes sobre el mismo objeto. La elección final se produjo posteriormente en función del encuadre, los elementos contenidos o cualquier otra característica de la toma.

Las fotografías, además de mostrar objetos, personas o acciones, contienen información temporal (Clark, 2010), pueden mostrarnos procesos presentes y sirven de recuerdo en el futuro o evocan momentos pasados que nos permiten replantear acciones presentes. En esta línea, algunos alumnos explican que las imágenes realizadas buscaban ser elementos evocadores de recuerdo. Así, mostraron espacios a los cuales acudían en otros momentos de su experiencia escolar y que en aquellos momentos eran inaccesibles para ellos. En el siguiente fragmento (procedente de la observación) se recoge la referencia que un alumno hace a la «bola», el edificio que acoge al alumnado de educación infantil y que recibe ese nombre por su forma de esfera.

Javier $\left(6^{\circ}\right)$ cuenta que él se hizo una foto en la bola por fuera del patio porque le recordaba a cuando eran muy pequeños y jugaban allí.

En contraposición, algunos alumnos han fotografiado espacios escolares que utilizan actualmente a modo de recuerdo futuro, dado que el próximo año cambian de centro (los alumnos de sexto de primaria irán al instituto).

Pablo $\left(6^{\circ}\right)$ expone que él y su primo (de segundo) han elegido el pabellón para poder recordar después dónde juegan. 
En la narración fotográfica de las experiencias vividas en los diferentes espacios educativos pueden primar los aspectos técnicos y estéticos de la imagen o bien su función meramente instrumental para el debate posterior (Thomson y Gunter, 2006). Por ello, en la mayoría de las ocasiones, la calidad artística de la fotografía quedaba supeditada o en un equilibrio desigual en referencia a la necesidad de trasmitir un mensaje sobre el espacio. Esto llevó a los chicos y chicas a usar la cámara de diferentes maneras. Mientras algunos dedicaban tiempo a seleccionar el encuadre, los actores que aparecían en la imagen o el ángulo, otros realizaban la instantánea sin atender a estos elementos y priorizando el diálogo posterior que tendrían sobre su fotografía. En estos casos, la imagen se convirtió más bien en un elemento físico para facilitar el recuerdo, un objeto para provocar un debate posterior sobre el asunto plasmado. En este sentido, podemos afirmar que abundaban más las instantáneas con una función principalmente elicitadora que las de mayor calidad técnica, lo cual podría ser entendido como un efecto indeseado de la forma en que se desarrolló la fase de fotografía individual. Sin duda, un mayor énfasis y más cuidado en el taller de formación de los estudiantes podría haber mejorado este aspecto. De igual forma, podemos concluir que los estudiantes tomaron la fase de diálogo posterior como el espacio principal de transmisión de mensajes, de forma que este proceso de captura de imágenes quedase en alguna medida como subsidiario de aquel.

\subsubsection{La fotografia participativa como promotora de diálogo e interpretación colectiva de las imágenes}

Atendiendo a la segunda de las fases de la fotografía participativa, las imágenes se convierten en objetos de análisis a través de estrategias de diálogo, reflexión, crítica e intersubjetividad, promoviendo nuevas preguntas e interpretaciones sobre los lugares representados (Novak, 2010).

Ya hemos dicho que las imágenes producidas por el alumnado eran miradas personales (Berger, 1972; Clark, 2010), lo que las convertía en objetos susceptibles de múltiples lecturas e interpretaciones. Por ello, en la experiencia que relatamos aquí, las tomas individuales se compartieron (en el panel del vestíbulo y en la asamblea), lo que ofreció la oportunidad de dialogar y reflexionar sobre ellas y de revisitarlas y reinterpretarlas colectivamente. Este diálogo compartido acerca de las fotografías tomadas permitió que cada estudiante explicara las razones que propiciaban que un espacio común se convirtiera en significativo para él o para ella y aceptara que un mismo espacio podía tener significados diversos o incluso opuestos para cada uno de ellos.

Por otra parte, como veremos más adelante en el ejemplo de «la selva», la fase de diálogo se confirmó como nuclear y fundamental en todo el proceso, hasta el punto de resultar determinante para desvelar ciertos espacios a los ojos adultos o incluso «crearlos» a través del mecanismo de la nominación.

Igualmente, el diálogo ha permitido romper la idea de «neutralidad» de los espacios y también de su funcionalidad unívoca, al tener acceso, a través del debate en la asamblea, a los sentidos personales que los alumnos atribuyen a 
estos lugares que han sido diseñados por adultos, muchas veces con objetivos ajenos a los expresados por los jóvenes.

\subsubsection{La fotografia participativa como herramienta de comunicación y difusión a audiencias más amplias}

Por último, la fotografía participativa se ha convertido también en una herramienta para el objetivo de alcanzar nuevas audiencias y ampliar el debate sobre los espacios escolares más allá del aula. El proceso no solo ha envuelto a una gran cantidad de actores en la escuela, puesto que los estudiantes participantes habían de solicitar consentimiento y explicar adecuadamente a sus compañeros qué estaban fotografiando y por qué, sino que también se había incluido una difusión interna de las fotografías en forma de panel expuesto en el vestíbulo del centro. Igualmente, el blog del aula permitió difundir la actividad llevada a cabo.

\section{2. ¿Qué nos dicen las fotografías sobre los espacios escolares en una lectura desde las geografias de la infancia?}

Presentamos aquí los resultados relativos a las interpretaciones que los alumnos realizan sobre los espacios escolares que habitan cotidianamente, centrándonos en cómo viven y en cómo experimentan estos lugares.

Encontramos, en primer lugar, que el alumnado documenta ampliamente los espacios alternativos de aprendizaje, caracterizados por las oportunidades

Imagen 2. Panel ubicado en el vestíbulo del centro con las fotografías y los textos

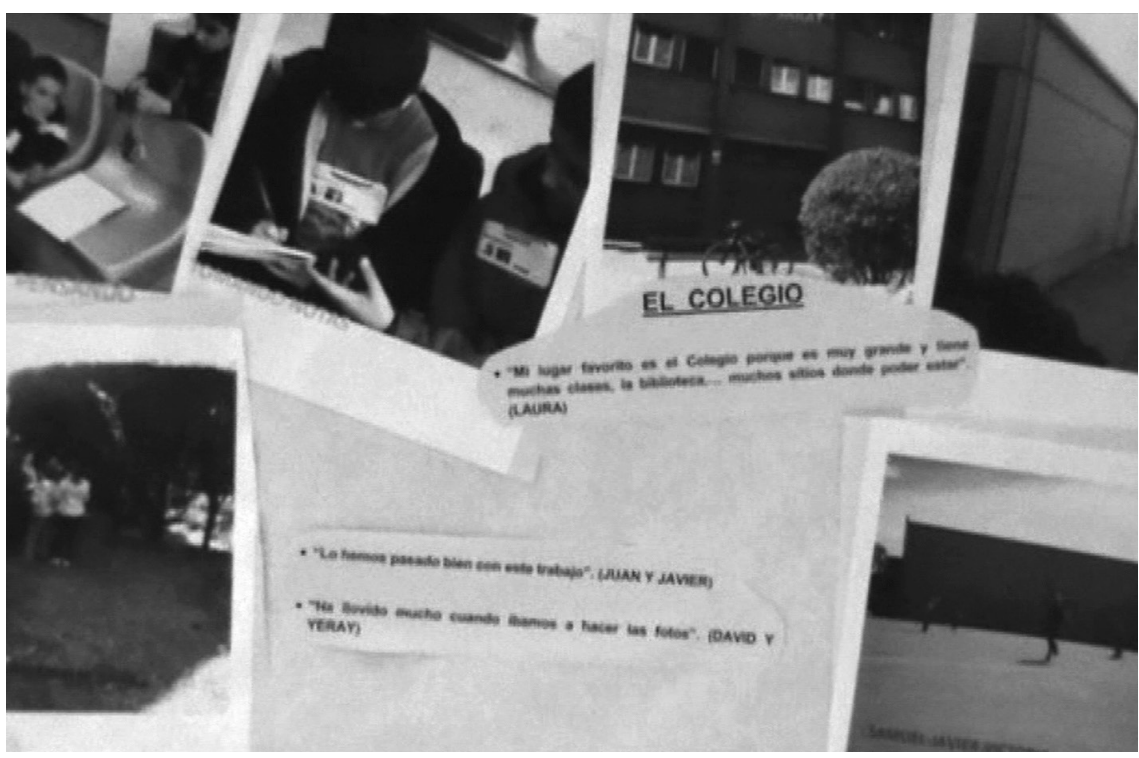

Fuente: elaboración propia. 
Imagen 3. Fotografía del pabellón

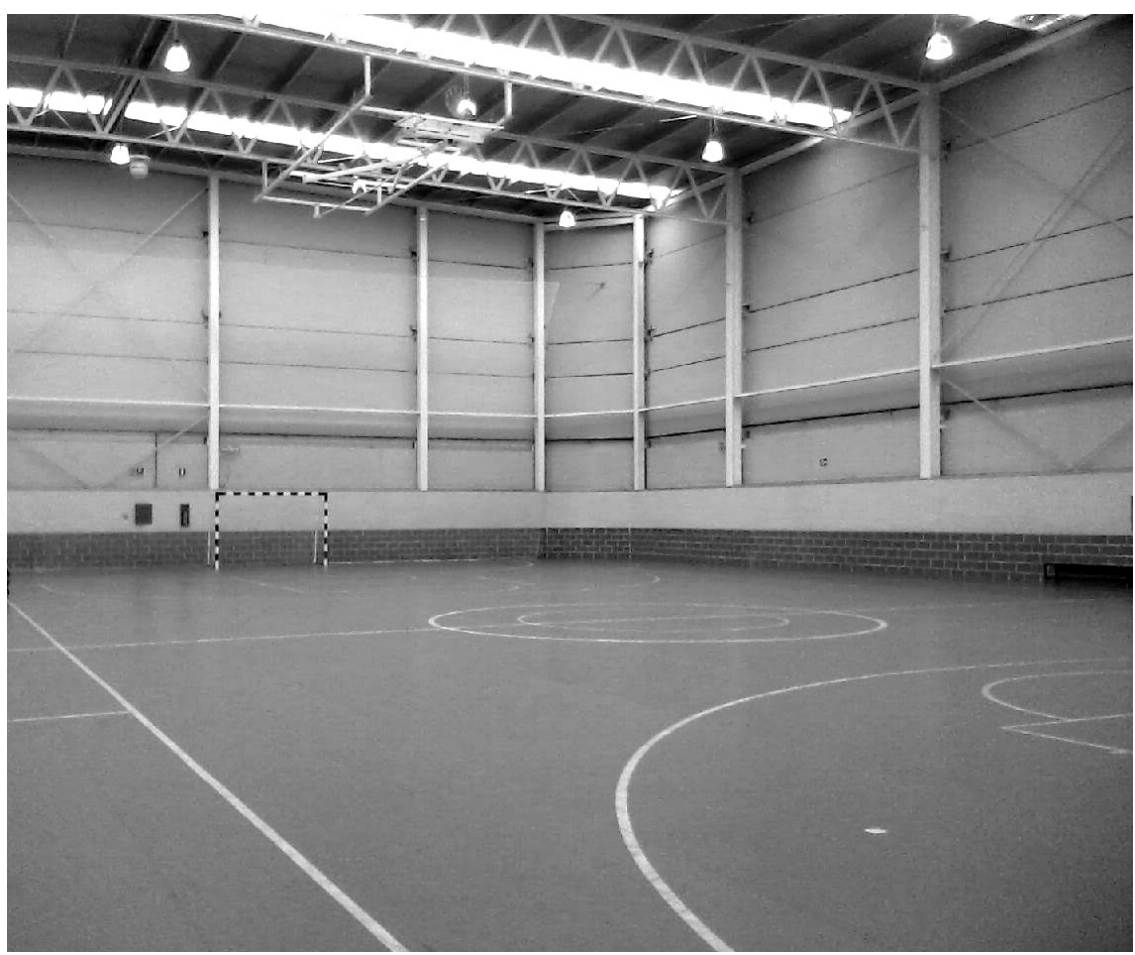

Fuente: elaboración por parte de los estudiantes.

que ofrecen de juego, manipulación y aprendizaje en la acción (el huerto, el polideportivo o el invernadero vertical). Son, sin duda, estos espacios los que mejor sintetizan sus preferencias. En su conjunto resumen lo que Holland et al. (2001) han denominado "la escuela informal», entendida como la interacción entre profesores entre sí; entre alumnos y profesores, y también entre alumnos entre sí (Lahelma, 2002), siendo estas relaciones, su construcción, deconstrucción y reconstrucción, las que definen en cierto grado los procesos y la vida escolar, así como las diferencias de poder y reconocimiento.

Daniel $\left(6^{\circ}\right)$ explica que han elegido el polideportivo porque a la gente le gusta jugar ahí al futbol o al baloncesto durante el recreo con los demás. (Diario de observación)

Las elecciones de los alumnos nos invitan también a pensar acerca de cómo se llevan a cabo los procesos de toma de decisiones sobre la organización y la gestión de la vida escolar en cada uno de los espacios. Entre los lugares más fotografiados encontramos el pabellón de deportes como un sitio relevante para ellos, por las actividades que allí realizan y por el tipo de relaciones que les permite establecer. 
Sin embargo, no todos los alumnos realizan la misma lectura de dicha zona. Ángel (de sexto curso) explica a sus compañeros que, en realidad, su fotografía no busca mostrar el edificio ni las actividades que actualmente se llevan a cabo en él, sino el espacio que ocupa, un lugar que antes de ser construido el pabellón servía de zona de juego alternativo (excavación).

Ángel (6o) relata que hizo la foto de donde estaba la zona. [...]. Él cuenta que le gusta el pabellón pero que considera que, como ya tienen el gimnasio, «es como tener dos». Es igual que el gimnasio, pero con gradas y esas «apenas se usan, la hemos usado como dos veces». Ángel añade que él eligió la zona antigua, donde está el pabellón ahora, porque recuerda que había un agujero en la pista y que él excavaba.

Esta nueva aportación sobre la imagen del pabellón provoca un proceso de revisión y relectura de dicho espacio que introduce una finalidad nueva en este diálogo: reivindicar el papel que los alumnos tienen en los procesos de toma de decisiones sobre el diseño de las zonas escolares y denunciar que la propuesta de sustituir la pista por el pabellón fue hecha exclusivamente por los adultos. Por otro lado, la fotografía no pretende representar lo evidente, sino lo invisible. No refleja un espacio presente y actualmente visible, sino un espacio pasado, ya inexistente, $y$ en este sentido es, en cierto modo, un elemento para la nostalgia.

Contrasta con lo dicho hasta el momento la evidencia de que ninguno de los estudiantes fotografió su aula como el espacio preferido de la escuela. Las aulas son el ejemplo paradigmático de lugares donde se escenifica la escuela oficial, aquella focalizada en el aprendizaje y el currículo formal. Su ausencia entre las fotos de los estudiantes las sitúa como zonas poco o nada apetecibles en su imaginario sobre la escuela, aunque este sea el lugar físico en el que permanecen la mayor parte del tiempo de su estancia escolar (¿o quizás precisamente por ello?).

La tutora $\left(6^{\circ}\right)$ expone que es curioso que en ningún caso hayan salido las aulas [...] llama la atención que lo que más les gusta del cole es jugar. Continúa contando que es singular porque luego cuando les preguntan a qué van al cole nadie dice a jugar sino a estudiar.

En todo caso, es posible deducir que los estudiantes plantean una clara división entre los espacios formales de aprendizaje, más regulados externamente, y los que permiten acceder a experiencias basadas en la experimentación, la manipulación y la acción más libre. También podemos confirmar, tal y como ya anunció Schmidt (2013), que un elemento determinante del nivel de «amigabilidad» que los estudiantes atribuyen a los espacios escolares tiene que ver con el nivel de presencia de la autoridad adulta. Sin duda, ello es testimonio a su vez de una fractura obvia para todos entre el currículum oficial, decidido por los adultos, y otras experiencias escolares que se desarrollan en lugares diferentes a las aulas. Las aulas no forman parte de las zonas que estos estudiantes consideran favoritas del centro, y ello podría explicarse no solo por el tipo de 
actividades que allí se desarrollan, sino también por las normas que regulan dicho espacio y que dificultan que los alumnos se adueñen del mismo o que sea considerado un «lugar propio».

En este sentido, podemos destacar que otros lugares más desregulados (el vestíbulo, el patio, la entrada, etc.) parecen ser escenarios más favorables para un tipo de relaciones con los docentes más amigables, menos verticales y más confidentes que no se desarrollan en el aula. Así, esta parece una zona de relación más equidistante entre el docente y todos los estudiantes, pero a la vez ofrece menor margen para lo personal y la expresión más libre del alumnado.

Los chicos y chicas fotografiaron, sin embargo, algunos lugares definidos por las normas de la escuela o condicionados por decisiones tomadas por los adultos que podemos denominar «espacios intermedios», por situarse a medio camino entre las aulas y las zonas de juego o de tránsito libre. Hay en ellos una nueva organización del uso y de la ocupación del espacio que, sin ser absolutamente libre, sí difiere de las normas habituales del aula, puesto que, tratándose de áreas de acceso limitado, son accesibles y elegibles para quienes lo deseen. Este es el caso del huerto escolar, al cual pueden ir los alumnos más pequeños según algunas normas.

Lucía $\left(6^{\circ}\right)$ propone que la huerta la puedan usar todos, [...] la usan hasta $4^{\circ}$ y a los $5^{\circ}$ y $6^{\circ}$ no les bajaban. (Diario de observación)

Una cualidad de este espacio intermedio es que propone reglas diferentes de uso a las establecidas en el aula y que es un lugar volcado en la acción, la manipulación y la creación, tal y como sucedía con los espacios informales elegidos.

Micaela $\left(2^{\circ}\right)$ cuenta que ellos han elegido el huerto porque le gustan las verduras y los orgánicos y además en el colegio se trabaja. [...]. J. (6 $\left.6^{\circ}\right)$ porque hay mucha naturaleza y tranquilidad. Sergio "porque puedes plantar muchas verduras». (Diario de observación)

Por otro lado, pocos estudiantes han señalado espacios como la biblioteca, la sala de actividades múltiples, el vestíbulo o el comedor como sus lugares favoritos. La biblioteca escolar, que es un espacio gestionado de forma autónoma por los estudiantes, es identificada por Leticia (sexto curso) como su lugar preferido.

Leticia $\left(6^{\circ}\right)$ cuenta que eligió la biblioteca porque le gustan los libros y leer: «Me siento bien cuando estoy ahí. No sé, recoger los libros, colocarlos».

Por sus propias normas de uso, la biblioteca parece ser un espacio de gran autonomía y un lugar donde ella puede desarrollar sin molestias una actividad que le gusta: leer. Es también este un buen ejemplo de cómo, en ocasiones, los estudiantes buscan zonas seguras que, por su configuración y sus normas, permiten realizar actividades más tranquilas, más autónomas e individuales y en las que los estudiantes pueden concentrarse o relajarse. Estos espacios, aunque 
Imagen 4. Fotografía del huerto

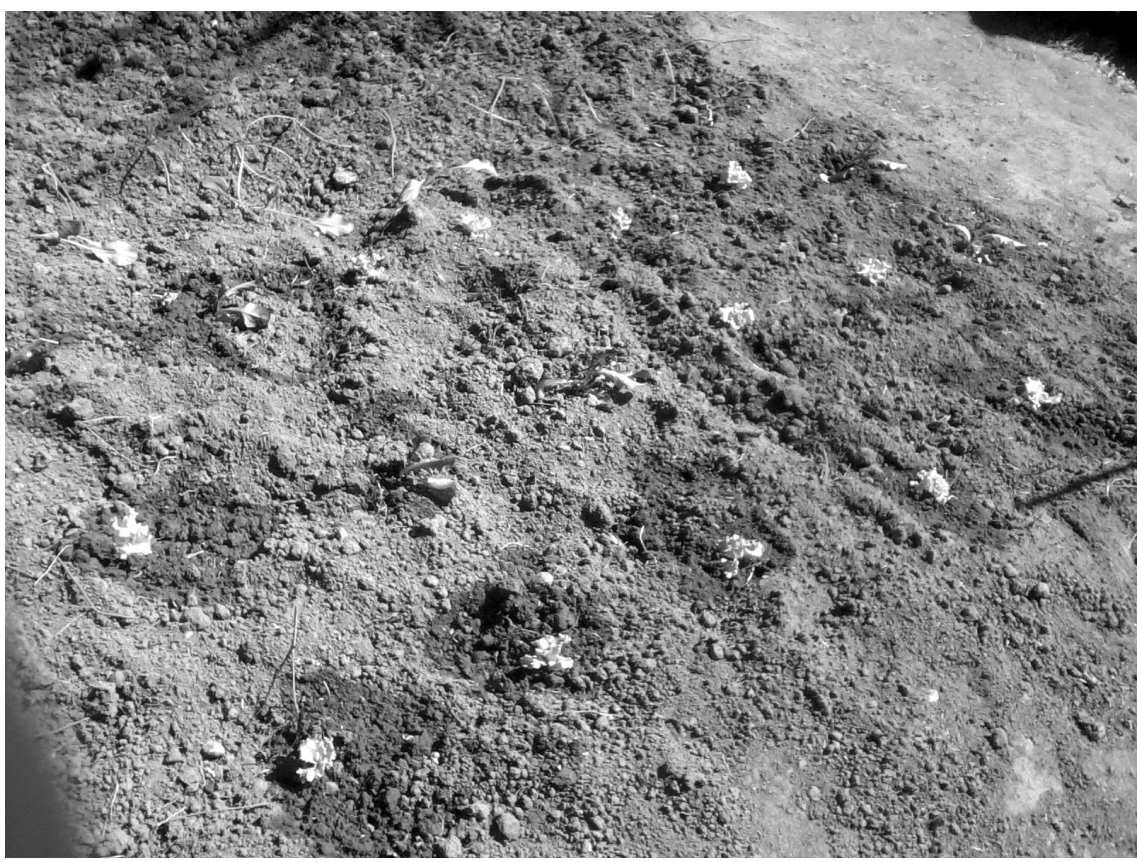

Fuente: elaboración por parte de los estudiantes.

generalmente son elegidos minoritariamente por el alumnado, constituyen un buen ejemplo de cómo la escuela respeta y promueve estilos diversos de subjetividad dentro del centro.

Los chicos y chicas también proponen en sus fotografías zonas que se definen por ser mundos alternativos, en las cuales se sumergen para transportarse a otros lugares y crear historias, proceso que ayuda a las personas a unirse a dichos espacios (Certeau, 1996). Quizás esto explique por qué los estudiantes destacan el espacio denominado "la selva» como uno de sus favoritos, por las posibilidades de imaginar y crear historias, personajes y aventuras. Este es un lugar reducido surgido entre el muro de la escuela y los arbustos que lo circundan. Se trata de un exiguo espacio de menos de un metro de anchura y con una altura irregular, según haya sido el crecimiento de las ramas de los árboles que lo constituyen.

Es llamativo, en primer lugar, que este espacio no surja inicialmente. No existen fotografías del mismo. Ningún escolar lo seleccionó como su lugar favorito, sino que fue en el transcurso del diálogo sobre las actividades que realizaban en otros lugares cuando emergió "la selva» y se convirtió en el aspecto central del diálogo. En el intento de explicar a las investigadoras cómo es este lugar, identifican una parte de «la selva» en la imagen que se había tomado para registrar la canasta de baloncesto. Esto convierte un elemento 
Imagen 5. Fotografía de «la selva»

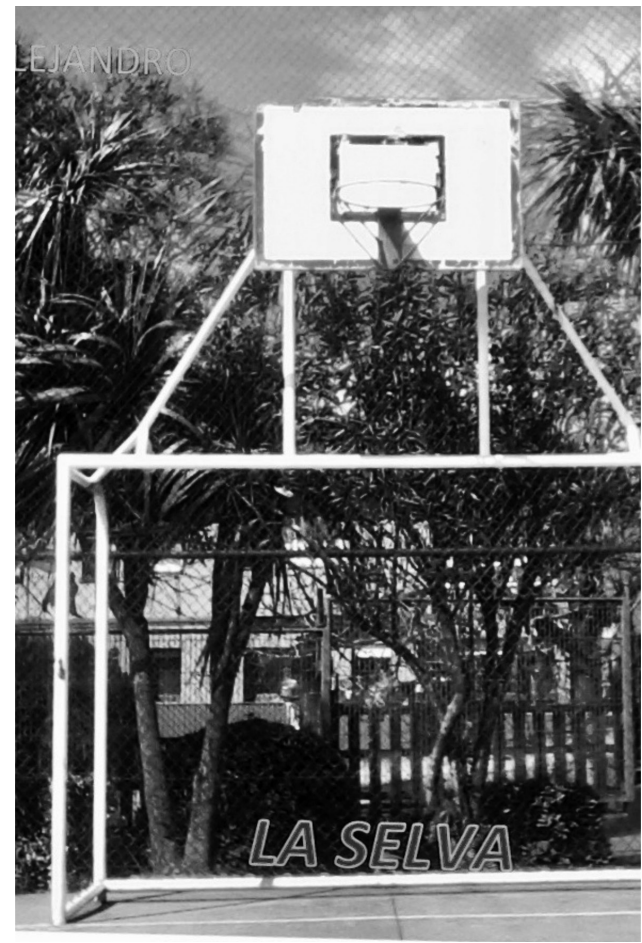

Fuente: elaboración por parte de los estudiantes.

residual de la fotografía en el objeto de toda la atención y transforma, a través de la conversación, todo el sentido inicial de la imagen, con lo que se pone de relieve el valor que adquieren el diálogo y la intersubjetividad en referencia a las instantáneas tomadas para la comprensión profunda de las geografías de la infancia en este caso.

Por otro lado, es destacable que todo el alumnado, independientemente del curso, lo señalase como un lugar relevante, que se mantenía en su recuerdo y que reflejaba un espacio lleno de significado para ellos.

Igualmente, la denominación que todos asignan a este lugar físico ubicado en un extremo del patio, en una esquina de la zona de recreo, rememora un lugar con algún peligro y pocas reglas. A pesar de que, por sus características reales, se encuentra muy alejado de una selva real, sí parece hacer referencia a un emplazamiento en cierto modo transgresor que evoca significados opuestos a la idea de la institución escolar como panóptico.

La tutora $\left(6^{\circ}\right)$ expone que le llama la atención cuando eligieron la selva, que tenía que ser un lugar prohibido porque es un seto y es peligroso y les pregunta por qué les gusta. Julia $\left(2^{\circ}\right)$ responde que le gusta porque pueden excavar. 
Diego $\left(6^{\circ}\right)$ cuenta que su hermana le ha hablado del lugar porque ella juega allí, coge palos y crean cosas, escalan... La tutora $\left(6^{\circ}\right)$ dice que es curioso que a todos les gusta porque es un sitio salvaje, donde esconderse... Leticia $\left(6^{\circ}\right)$ comenta que a su hermana también le gusta porque hacen casas y trampas porque les gusta las cosas creativas y hacer cosas nuevas.

\subsection{Espacios animados versus espacios vacios}

Por último, es necesario centrar la atención sobre cómo se producen las imágenes, qué recogen y, por ende, qué queda fuera del marco, además de cómo se representan a sí mismos. En la consigna del proyecto de indagación se explicitó que las fotografías no únicamente tenían como propósito visualizar los aspectos físicos del espacio, sino también las acciones, las relaciones y los procesos que en ellos se desarrollan.

Sin embargo, en la mayoría de los casos, el alumnado optó por fotografiar el aspecto físico del lugar a través de planos generales que mostraban zonas vacías, sin personas, con la mayor amplitud posible. De este modo, los espacios se presentaron como lugares deshabitados, en los que la actividad cotidiana de la vida escolar no era un elemento que quedara recogido por la presencia de personas en acción ni por el uso de metáforas que pudieran reflejarlo.

Imagen 6. Espacios inhabitados

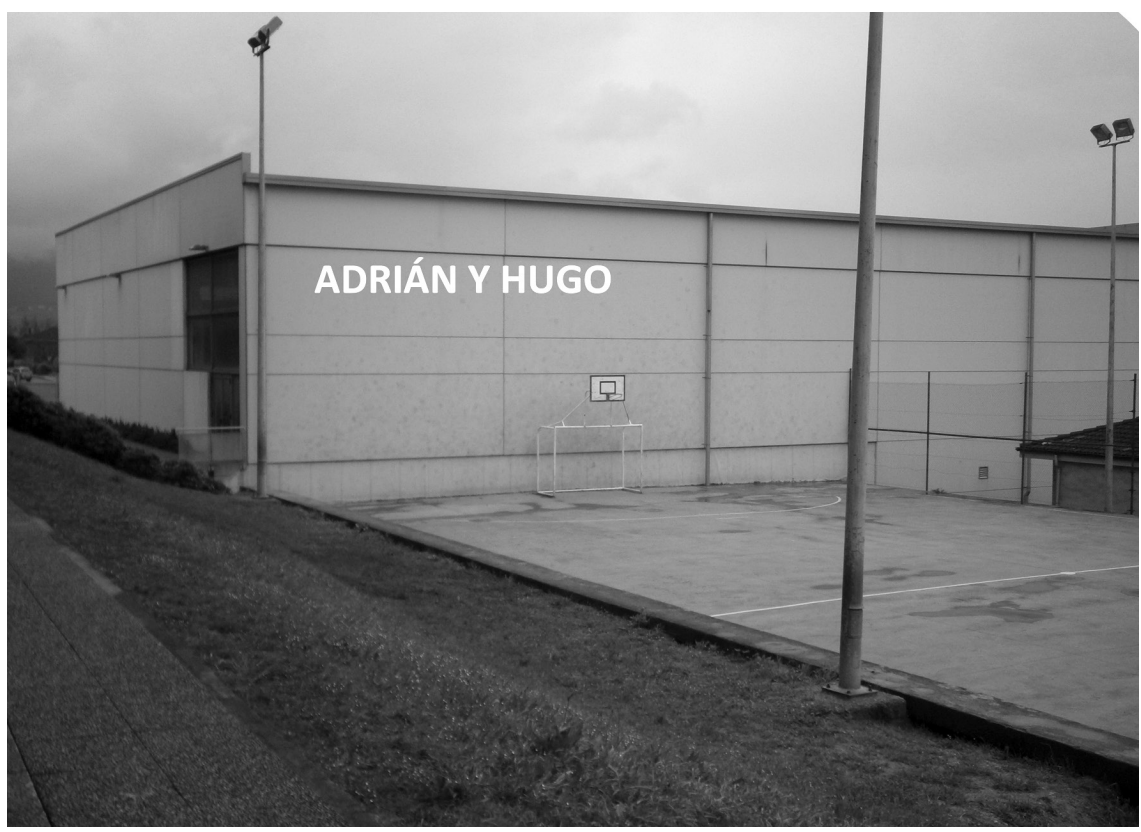

Fuente: elaboración por parte de los estudiantes. 
Imagen 7. Espacios habitados

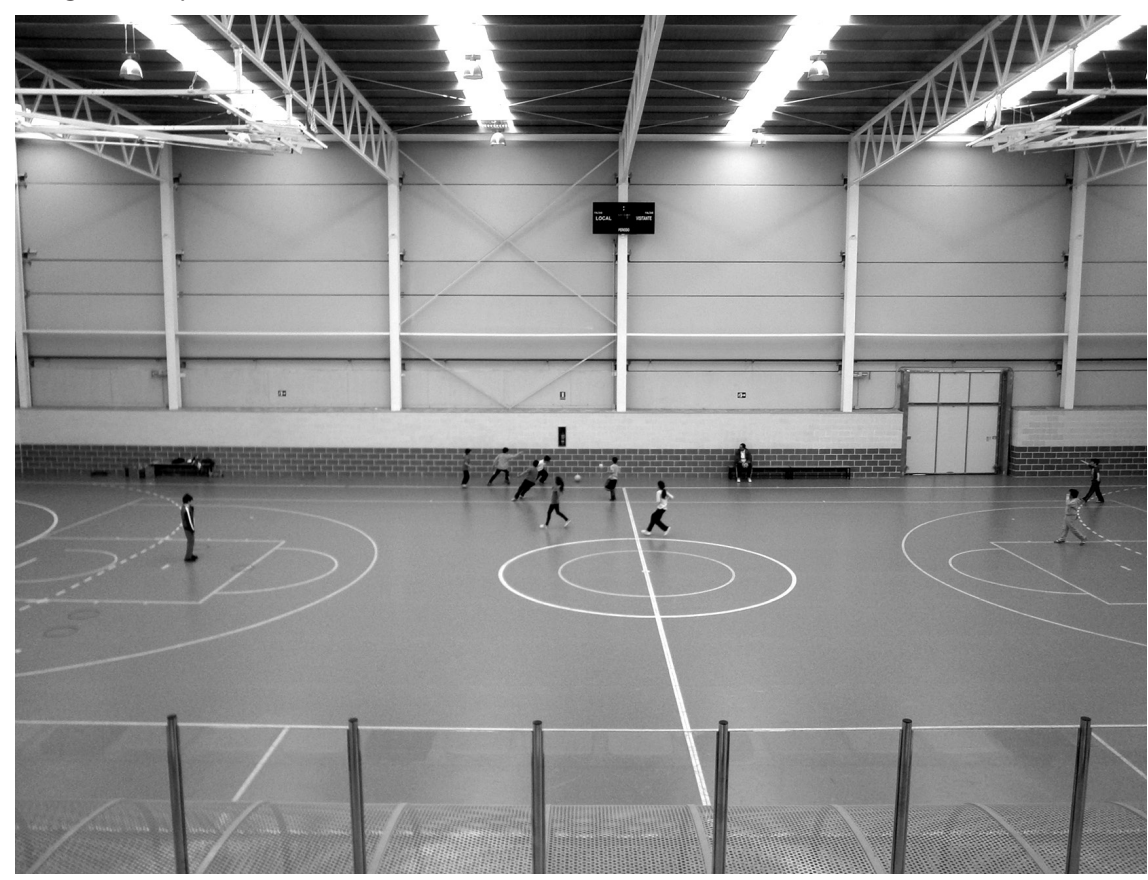

Fuente: elaboración por parte de los estudiantes.

Únicamente un grupo reducido de alumnos mostraron esas relaciones y esos procesos a través de la incorporación a la fotografía de personas y actividades. Entre ellos encontramos diferencias evidentes. Algunos se situaron a sí mismos como los elementos de mayor presencia ocupando el primer plano de la imagen. Otros buscaron conseguir el equilibrio entre su presencia y el espacio.

Si nos interrogamos sobre las imágenes, de ellas emergen dos aspectos: por un lado, la elección de representarse como sujetos estáticos, puesto que posan delante de la cámara, inmóviles, lo que trasmite una idea de los espacios como lugares sin acción. Por otro lado, llama la atención que una generación que convive con el selfie como medio de expresión no eligiera ese tipo de plano para combinar su presencia y el espacio.

En contraposición a unas instantáneas que nos mostraban espacios inhabitados o sin acción encontramos el trabajo de dos parejas. Una de ellas elaboró una fotografía en la que se incluía a sí misma realizando la actividad principal que llevaba a cabo en dicho lugar: jugando en la pista del patio. La otra incorporó a compañeros realizando educación física en el pabellón, la actividad más recurrente allí. Estas fotografías nos devolvían a la idea de espacios habitados, llenos de relaciones, actividades y procesos que daban sentido a los lugares y que configuraban la vida escolar. 


\section{Conclusiones}

Hasta aquí hemos presentado una investigación que busca explorar las geografías de la infancia en la vida cotidiana de los niños en la escuela a través del análisis del uso, de la ocupación y de las actividades que realizan en los espacios escolares. El sentido último del trabajo es contribuir al reconocimiento de los estudiantes como agentes de los procesos educativos y cuya experiencia sobre los espacios es relevante para los procesos de mejora escolar que tienen en cuenta su voz. Si bien es cierto que el entorno escolar tiene la capacidad de establecer materialmente unas condiciones que favorecen determinadas prácticas pedagógicas, a la vez, el trabajo realizado nos confirma que la experiencia de los estudiantes en relación con estos espacios no coincide necesariamente con la que espera el adulto que los diseña o los prescribe.

El análisis se despliega en el marco de la fotografía participativa desarrollada por estudiantes de segundo y sexto de educación primaria (8 y 12 años) que se propusieron fotografiar su lugar favorito de la escuela. La combinación del lenguaje visual (fotografía) y el posterior debate conjunto acerca de cada una de las imágenes ha permitido a todos los alumnos construir y compartir su particular mirada sobre los espacios académicos, así como facilitar el diálogo, la reflexión y la construcción colectiva de significados.

En consecuencia, reconocemos que la estrategia de la fotografía participativa nos proporciona una oportunidad para mostrar ideas e interpretaciones individuales, pero también es valiosa como elemento de encuentro y de revisión colectiva que propicia una visión más compleja y múltiple sobre los espacios escolares. Destaca en este sentido que la fotografía participativa se ha mostrado como una herramienta útil para los fines de la participación inclusiva por ser accesible a todos, por favorecer la construcción de interpretaciones y reinterpretaciones colectivas en un diálogo deliberativo y por su capacidad de dar visibilidad a puntos de vista minoritarios entre los estudiantes.

Es en este diálogo sobre las imágenes tomadas donde se evidencia la existencia de múltiples infancias y, por tanto, de múltiples geografías de la infancia, pues cada alumno, aun compartiendo el mismo espacio (por ejemplo: el pabellón deportivo), ha mostrado una experiencia diversa del mismo. En este sentido, tal y como afirman Coronel y Rodríguez (2013), la fotografía se ha revelado no solo como una ventana al mundo exterior (en este caso la escuela), sino también a las diferentes subjetividades de los estudiantes. La descripción escrita y el debate oral de los estudiantes sobre su imagen ha permitido esclarecer en parte la relación entre ambos mundos, que se materializa en esa imagen que cada uno ha elegido.

Por último, nuestro trabajo muestra que las fotografías son modificadas, ampliadas y revisadas a consecuencia del diálogo entablado acerca de ellas. Tal y como hemos visto en varios ejemplos, no siempre significan lo que muestran, y por ello deben ser escrutadas junto con los estudiantes. Las imágenes nos han enseñado que los alumnos eligen lugares más alejados de la autoridad 
adulta; que en ellas predominan las zonas de acción, manipulación y juego libre, y que estas zonas se constituyen como lugares fundamentales para la formación de identidades, alejados de las prácticas reguladoras de la escuela. También hemos aprendido que la mirada de los adultos sobre los espacios no siempre es capaz de apreciar las resignificaciones que son realizadas por los estudiantes, que ellos se sienten excluidos de ciertas decisiones importantes que les afectan o que la memoria ligada a los espacios o la experiencia individual de alumnos concretos muchas veces está anegada por las voces hegemónicas o por una visión tradicional de la infancia.

\section{Referencias bibliográficas}

ABAD, Javier (2006). «La escuela como ámbito estético según la pedagogía Reggiana». Recuperado de <http://www.vitoria-gasteiz.org/wb021/http/contenidosEstaticos/ adjuntos/es/33/07/43307.pdf>.

Asamblea General de las Naciones Unidas (1989). Convención sobre los Derechos del Niño. Madrid. Unicef.

BANKS, Marcus (2010). Los datos visuales en investigación cualitativa. Madrid: Morata.

BARKER, John y SMITH, Fiona (2012). «What's in focus?: A critical discussion of photography, children and young people». International Journal of Social Research Methodology, 15 (2), 91-103.

BERGER, John (1972). Modos de ver. Barcelona: Gustavo Gili.

BuCKNALL, Sue (2012). Children as researchers in primary schools: Choice, voice, and participation. Londres: Routledge.

Ceballos, Noelia; Susinos, Teresa y SaIz, Ángela (2016). «How Can We Improve through Pupil Participation? An Infants School Experience». Journal of Research in Special Educational Needs, 16 (1), 583-586. $<$ https://doi.org/10.1111/1471-3802.12189>

Certeau, Michel (1996). La invención de lo cotidiano. I: Artes de hacer. México DF: Universidad Iberoamericana.

ClaRK, Alison (2010). Transforming children's spaces: Children's and adults' participation in designing learning environments. Londres: Routledge.

COOPER, Victoria (2017). «Lost in translation: Exploring childhood identity using photo-elicitation». Children's Geographies, 15 (6), 625-637. <https://doi.org/10.1080/14733285.2017.1284306>

Coronel, José Manuel y RodríGuez, Ivan (2013). «Let me put It another way: Methodological considerations on the use of participatory photography based on an experiment with teenagers in secondary schools». Qualitative Research in Education, 2 (2), 98-129.

Croghan, Rosaleen; Griffin, Christine; Hunter, Janine y Phoenix, Ann (2008). «Young people's constructions of self: Notes on the use and analysis of the photoelicitation methods». International Journal of Social Research Methodology, 11 (4), 345-356.

DocketT, Sue; EINARSDOTTIR, Johanna y PerRY, Bob (2009). «Researching with children: Ethical tensions». Journal of Early Childhood Research, 7 (3), 283-298.

Doval, María Isabel; MarTínez-Figueira, María Esther y Raposo, Manuela (2013). «La voz de sus ojos: La participación de los escolares mediante Fotovoz». Revista de Investigación en Educación, 3 (11), 150-171. 
Ergler, Christina; Kearns, Robin; Witten, Karen y Porter, Gina (2016). «Digital methodologies and practices in children's geographies». Children's Geographies, 14 (2), 129-140.

FIELDING, Michael (2011). «La voz del alumnado y la inclusión educativa: Una aproximación democrática radical para el aprendizaje intergeneracional». Revista Interuniversitaria de Formación del Profesorado, 25 (1), 31-61.

FLICK, Uwe (2009). Introducción a la investigación cualitativa. Madrid: Morata.

GiBBS, Graham (2012). El análisis de datos cualitativos en Investigación Cualitativa. Madrid: Morata.

GIDDINGS, Robert y YARWOOD, Richard (2005). «Growing up, going out and growing out of the countryside: Childhood experiences in rural England». Children's Geographies, 3 (1), 101-114. <https://doi.org/10.1080/14733280500037331>

Holland, Janet; Gordon, Tuula; Lahelma, Elina y Escobar, Adriana (2001). «Mapeando el género y la ciudadanía en las escuelas». Nómadas, 8 (1), 24-35.

Holloway, Sarah (2014). "Changing children's geographies». Children's Geographies, $12(4), 377-392$. <https://doi.org/10.1080/14733285.2014.930414>

HorTON, John; KrafTl, Peter y TuCKer, Faith (2008). «The challenges of 'Children's Geographies': A reaffirmation». Children's Geographies, 6 (4), 335-348. <https://doi.org/10.1080/14733280802338049>

KINCHELOE, Joe (2007). «Clarifying the purpose of engaging students as researchers». En: THIESSEN, Dennis y COOK-SHATER, Alison (eds.). International handbook of student experience in elementary and secondary school. Springer Netherlands, 745-774.

Kvale, Steinar (2011). Las entrevistas en investigación cualitativa. Madrid: Morata.

LAHELMA, Elina (2002). «School is for meeting friends: Secondary school as lived and remembered». British Journal of Sociology of Education, 23 (3), 367-381. <https://doi.org/10.1080/0142569022000015418>

Maguire, Sarah y SHIRLOw, Peter (2005). «Shaping childhood risk in post-conflict rural northern Ireland». Children's Geographies, 2 (1), 69-82. <https://doi.org/10.1080/1473328032000168778>

MatTHEWS, Hugh y Limb, Melani (1999). "Defining an agenda for the geography of children: Review and prospect». Progress in Human Geography, 23 (1), 61-90. <https://doi.org/10.1191/030913299670961492>

MiLls, Sarah (2017). «Voice: Sonic geographies of childhood». Children's Geographies, 15 (5), 1-14. $<$ https://doi.org/10.1080/14733285.2017.1287879>

Niemi, Reeta; Kumpulainen, Kristiina y LipPonen, Lasse (2015). «Pupils as active participants: Diamond ranking as a tool to investigate pupils' experiences of classroom practices». European Educational Research Journal, 14 (2), 138-150. <https://doi.org/10.1177/1474904115571797>

NOvaK, David (2010). «Democratizing qualitative research: Photovoice and the study of human communication». Communication Methods and Measures, 4 (4), 291-310.

Ortiz Guitart, Anna (2007). "Geografías de la infancia: Descubriendo "nuevas formas" de ver y de entender el mundo». Documents d'Anàlisi Geogràfica, 49, $197-216$.

Ortiz Guitart, Anna; Prats Ferret, Maria y Baylina Ferré, Mireia (2012). «Métodos visuales y geografías de la infancia: Dibujando el entorno cotidiano». Scripta Nova: Revista Electrónica de Geografía y Ciencias Sociales, 16. 
PARrilla, Ángeles (2010). «Ética para una investigación inclusiva». Revista Educación Inclusiva, 3 (1), 165-174.

PHILliPS, Richard (2001). «Geographies of childhood: Introduction». Area, 33 (2), 117-118. <https://doi.org/10.1111/1475-4762.00014>

PRINS, Esther (2010). «Participatory photography: A tool for empowerment or surveillance?». Action Research, 8 (4), 426-443.

Robson, Elsbeth; HorTOn, John y KRAFTL, Peter (2013). «Children's Geographies: Reflecting on Our First Ten Years». Children's Geographies, 11 (1), 1-6. <https://doi.org/10.1080/14733285.2012.752665>

SAnOn, Marie-Anne; Evans-Agnew, Robin A. y BouTAin, Doris (2014). «An exploration of social justice intent in photovoice research studies from 2008 to 2013». Nursing Inquiry, 21 (3), 212-226.

SCHMIDT, Sandra J. (2013). "Claiming our turf: Students civic negotiation of the public space of school». Theory and Research in Social Education, 41 (4), 535-551. <https://doi.org/10.1080/00933104.2013.840717>

SMOYER-TOMIC, Karen; HewKO, Jared y HodGSON, John (2004). «Spatial accessibility and equity of playgrounds in Edmonton, Canada». The Canadian Geographer, 48 (3), 287-302. <https://doi.org/10.1111/j.0008-3658.2004.00061.x>

SPILSBURY, James (2005). «"We don't really get to go out in the front yard”: Children's home range and neighborhood violence». Children's Geographies, 3 (1), 79-99. <https://doi.org/10.1080/14733280500037281>

Susinos, Teresa y Ceballos, Noelia (2012). «Voz del alumnado y presencia participativa en la vida escolar. Apuntes para una cartografía de la voz del alumnado en la mejora educativa». Revista de Educación, 359, 24-44.

SusinOS, Teresa y HAYA, Ignacio (2014). «Developing student voice and participatory pedagogy: a case study in a Spanish primary school». Cambrigde Journal of Education, 44 (3), 385-399.

Thomson, Pat (ed.) (2008). Doing Visual Research with Children and Young People. Abington: Routledge.

Thomson, Pat y GunTer, Helen (2006). «From "consulting pupils" to "pupils as researchers": A situated case narrative». British Educational Research Journal, 32 (6), 839-856. <https://doi.org/10.1080/01411920600989487>

Thomson, Sarah (2005). "Territorialising' the primary school playground: Deconstructing the geography of playtime». Children's Geographies, 3 (1), 63-78. $<$ https://doi.org/10.1080/14733280500037224>

TOlfreE, David y WoODHEAD, Martin (1999). «Tapping a key resource». Early Childhood Matters, 91, 19-23.

TUCKER, Faith (2003). «Sameness or difference?: Exploring girls' use of recreational spaces». Children's Geographies, 1 (1), 111-124. <https://doi.org/10.1080/14733280302187>

WANG, Caroline (2003). «Using photovoice as a participatory assessment and issue selection tool: A case study with the homeless in Ann Arbor». En: MinKLER, Meredith y WALLERSTEIN, Nina (eds.). Community-based participatory research for health. San Francisco: Jossey-Bass, 179-196.

WANG, Caroline y BuRRIS, Mary Ann (1994). «Empowerment through photo novella: Portraits of participation». Health Education Quarterly, 21 (2), 171-186. 